\title{
CONDIÇOEES DE ARMAZENAMENTO NA VIABILIDADE E DORMÊNCIA DE SEMENTES DE VIDEIRA (')
}

\author{
JOCELY ANDREUCCETTI MAEDA $\left({ }^{2}\right)$, MARIA DE FATTIMA DOMINGOS ALEIXO PEREIRA $\left({ }^{3}\right)$ \\ e MAURILO MONTEIRO TERRA $\left({ }^{4,5}\right)$
}

\begin{abstract}
RESUMO
A manutenção da viabilidade de sementes por perfodos mais ou menos longos está bastante relacionada com as condiçoes em que elas sâo armazenadas. Temperatura e teor de umidade estão entre os fatores que mais afetam sua longevidade. $O$ objetivo deste trabalho é o estudo da viabilidade e dormencia de uva do cultivar Patrícia, armazenada durante 24 meses em dois tipos de recipientes - em vidro hermético e saco de papel - a temperaturas de 10,20 e $30^{\circ} \mathrm{C}$, com dois diferentes teores iniciais de umidade. A porcentagem de sementes dormentes e viáveis foi determinada bimestralmente durante os primeiros 12 meses, e semestralmente nos periodos mais longos. O armazenamento não quebrou a dormencia das sementes de uva em nenhuma das condiçoes estudadas. Enquanto as sementes frescas mostraram melhor conservação a $10^{\circ} \mathrm{C}$ quando embaladas em vidro hermético, sementes secas se conservaram melhor a $20^{\circ} \mathrm{C}$. Em saco de papel, foram poucas as diferenças encontradas entre os tratamentos, a nao ser nos períodos finais do armazenamento, quando $20^{\circ} \mathrm{C}$ se mostrou a pior temperatura de conservaçao. Dessa maneira, a dorméncia nao foi alterada pelo armazenamento, nas condiçoes estudadas, e a viabilidade foi bastante afetada tanto pelo tipo de embalagem como pela temperatura de armazenamento.
\end{abstract}

Termos de indexação: uva; sementes; armazenamento; viabilidade; germinação; dormência.

$\left({ }^{1}\right)$ Parte da Dissertação apresentada pelo primeiro autor à Universidade Estadual de Campinas, em 1982, para obtenção do título de Mestre em Cièncias Biológicas na área de Biologia Vegetal. Recebido para publicação em 25 de maio de 1984.

${ }^{2}$ ) Seção de Sementes, Instituto Agronómico (IAC), Caixa Postal 28, 13100 - Campinas (SP).

(3) Departamento de Fisiologia Vegetal, Universidade Estadual de Campinas (SP).

$\left({ }^{4}\right)$ Seção de Viticultura, IAC.

(5) Com bolsa de suplementaçăo do CNPq. 


\section{INTRODUÇÃO}

A semente tem grande importância como alimento e como mecanismo de perpetuação da espécie. Neste último caso, torna-se primordial a informação sobre a porcentagem de germinação do lote antes de se efetuar sua semeadura.

A propagação da videira se dá por via vegetativa, por meio de estacas. No entanto, pesquisas sobre a fisiologia da germinação e armazenamento das sementes são importantes, uma vez que são utilizadas para estudos de melhoramento genético, ou seja, para produção de novas variedades (WINKLER, 1965).

A máxima qualidade da semente é atingida por ocasião da sua maturidade fisiológica. A partir desse ponto, inicia-se a deterioração, que pode ser retardada ou mantida numa velocidade mínima por condiçбes ideais de colheita, secagem, armazenamento, numa tentativa de manter a qualidade tão próximo quanto possível do ponto mais alto atingido (HARRINGTON, 1972).

Uma vez conseguidas sementes de elevada qualidade, nem sempre sđ̃o utilizadas imediatamente, necessitando então armazenamento. Tendo em vista que este é um fator responsável por grande perda da viabilidade, torna-se necessário o levantamento de alguns estudos.

A vida máxima de uma semente durante o armazenamento depende sobremaneira das condiçós ambientes a que ela está sujeita (DELOUCHE, 1968).

Muitos fatores, tais como umidade, temperatura, trocas gasosas, características do tegumento da semente, maturidade, infestação por insetos e microflora, podem determinar a longevidade de sementes sob condiçóes naturais ou controladas de armazenamento. Assim, a semente pode ser produzida sob um sistema rigoroso de inspeção, colheita apropriada, e processada para a mais alta pureza, porém pode ser perdida se armazenada sob condiçoes precárias ou embalada com alto teor de umidade.

Dessa maneira, sementes de uva foram armazenadas durante 24 me-

ses em vidro hermético e saco de papel a temperaturas de $10^{\circ} \mathrm{C}, 20^{\circ} \mathrm{C}$ e $30^{\circ} \mathrm{C}$, acompanhando-se dados de sua viabilidade e dormência durante o armazenamento.

\section{MATERIAL E MÉTODOS}

Foram usadas sementes da videira cv. Patrícia colhidas em janeiro de 1979, conduzidas no sistema de manjedoura aberta na Estaçâo Experi- 
mental de Jundiaí do Instituto Agronômico. 'Patrícia' é um híbrido complexo, produzido no Instituto Agronomico de Campinas (IAC 871-41).

Para utilização neste trabalho, as sementes foram retiradas, espremendo-se as bagas contra uma peneira, lavadas, e deixadas secar sobre pano, na sombra, para retirada do excesso de umidade. Em seguida, foi feito tratamento das sementes com o fungicida Arasan 75 (Du Pont), com o ingrediente ativo Thiram (75\%) na proporção de $330 \mathrm{~g}$ do produto na forma comercial por $100 \mathrm{~kg}$ de sementes.

As sementes recém-colhidas e secas na sombra foram subdivididas em dois lotes: um deles constituiu o lote de sementes frescas e, o outro, o lote de sementes secas, foi mantido em secador a $30^{\circ} \mathrm{C}$ com circulação forçada de ar durante 24 horas.

Esses dois lotes de sementes foram acondicionados em dois tipos de embalagens - vidro hermético e saco de papel - e colocados a diferentes temperaturas $-10,20$ e $30^{\circ} \mathrm{C}$.

Amostras de cada tratamento foram retiradas a cada dois meses para efetuar os testes de laboratório, até 12 meses, e a seguir, de seis em seis meses até completar 24 meses de armazenamento.

Para determinação do teor de umidade inicial, duas amostras de $50 \mathrm{~g}$ de sementes foram pesadas e colocadas em latas abertas em estufa com ventilação adequada, mas não forçada, e temperatura de $105 \pm 3^{\circ} \mathrm{C}$. Decorridas 24 horas, as sementes foram novamente pesadas, e a porcentagem de umidade, calculada para cada amostra, aplicando-se a seguinte equação:

$$
\text { Umidade }(\mathrm{U}) \%=\frac{100(\mathrm{P}-\mathrm{p})}{\mathrm{P}-\mathrm{t}}
$$

onde $\mathbf{P}$ é o peso bruto inicial da amostra, $\mathbf{p}$, o peso bruto final $\mathbf{e}, \mathbf{t}$, o peso do recipiente (BRASIL, 1976).

Para execução do teste de germinação, as sementes foram colocadas em germinador da marca "FANEM" com temperatura alternada de $20-30^{\circ} \mathrm{C}$, sendo $20^{\circ} \mathrm{C}$ durante 16 horas e $30^{\circ} \mathrm{C}$ durante 8 horas.

O substrato utilizado foi o papel toalha especial para germinação. As sementes foram colocadas sobre toda a extensáo do papel umedecido, que foi enrolado e colocado na posição vertical em germinador com sistema constante de circulação de água, o que permite manter sempre úmidos os substratos, a fìm de dar às sementes a quantidade de água necessária para sưa germinação, porém não em excesso.

A verificação do namero de sementes germinadas foi efetuada a cada sete dias durante 28 dias. Considerou-se germinada toda semente que, pela emergência e desenvolvimento das estruturas essenciais de seu embrião, produziu uma plântula normal. 
Como semente dormente, foi considerada aquela intumescida, que absorveu água, porém não germinou até o último dia do experimento. Nesse caso, as sementes eram resistentes à compressáo com o dedo. A semente morta, pelo contrário, estourava facilmente quando comprimida contra a mesa.

A porcentagem de viabilidade das sementes foi obtida pela soma das sementes germinadas e dormentes.

O delineamento estatístico utilizado em todos os experimentos foi o completamente casualizado (SNEDECOR, 1962). Os dados em porcentagem foram transformados em arco seno $\sqrt{\%}$ para fins de normalizar a sua distribuição. $O$ delineamento de tratamentos foi um fatorial $2 \times 3$ para embalagem e temperatura, em ensaios inteiramente casualizados. Comparaçoes entre médias de temperaturas foram feitas pelo teste de Tukey ao nível de 5\% (GOMES, 1963).

\section{RESULTADOS E DISCUSSÃO}

Em geral, baixo teor de umidade, baixa temperatura e baixa tensão de oxigênio aumentam a longevidade de sementes durante o armazenamento (BARTON, 1961).

Na maioria das espécies, o período de viabilidade da semente é dependente da temperatura, teor de umidade e pressão de oxigênio durante o armazenamento; decrescendo qualquer um desses fatores, aumenta o período de viabilidade (ROBERTS, 1973).

COSTACURTA et alii (1978) concluíram que, para sementes de uva, temperaturas mais baixas durante o armazenamento são mais favoráveis à germinaçăo, embora os autores só tenham testado $22^{\circ} \mathrm{C}$ e $27^{\circ} \mathrm{C}$.

Os resultados do presente trabalho indicaram que as temperaturas mais baixas de armazenamento foram mais favoráveis à manutenção da capacidade germinativa das sementes.

O lote de sementes frescas de uva apresentou um teor de umidade de $16,21 \%$. Sementes que foram submetidas à secagem tiveram esse teor reduzido para $10,34 \%$.

A germinação de sementes armazenadas frescas foi afetada pelo tipo de embalagem e temperatura de armazenamento. Em vidro hermético (Figura 1A), esse processo foi efetuado significativamente pela temperatura de conservação, em todas as épocas, com exceção dos 2 primeiros meses. Sementes conservadas a $30^{\circ} \mathrm{C}$ perderam quase totalmente a capacidade de germinar após 4 meses. A conservação a $10^{\circ} \mathrm{C}$ ou $20^{\circ} \mathrm{C}$ foi indiferente para a germinação das sementes até 6 meses da estocagem. Sementes armazenadas por períodos mais longos mantiveram a capacidade de germinação quando 
conservadas a $10^{\circ} \mathrm{C}$, enquanto demonstraram rápida redução na germinação a partir de 8 meses, quando a $20^{\circ} \mathrm{C}$.

Ao comparar o efeito de temperaturas quando as sementes frescas foram armazenadas em saco de papel (Figura 1B), notaram-se melhores resultados com a conservação a $20^{\circ} \mathrm{C}$. As diferenças foram estatisticamente significativas aos $8,12,18$ e 24 meses. As temperaturas 10 e $30^{\circ} \mathrm{C}$ apresentaram efeitos semelhantes na maioria das épocas analisadas.

$O$ efeito da embalagem sobre a germinação de sementes secas não foi significativo em nenhuma das épocas analisadas (Figura 2). A temperatura mostrou efeito significativo apenas aos 2 meses e a partir do $12 \%$ mês de armazenamento, independentemente do tipo de embalagem, ocorrendo ainda interação significativa entre temperatura e embalagem. Isso significa que,

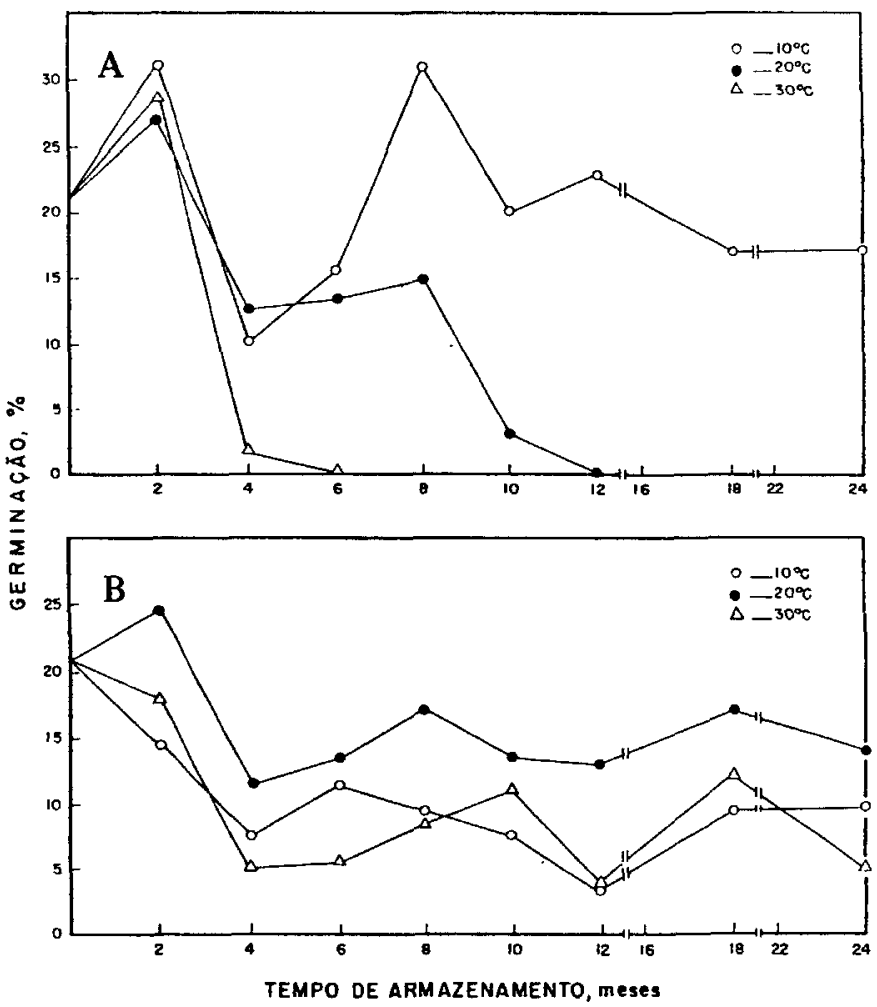

FIGURA 1 - Condiçoes de armazenamento de sementes frescas, e seus efeitos na germinaçđo em temperatura alternada de $20-30^{\circ} \mathrm{C}$ apos 28 dias: A: Sementes armazenadas em vidro hermético, a diferentes condiçoes de temperatura; B: Sementes armazenadas em saco de papel, a diferentes condiçoes de temperatura. 
dentro de cada embalagem, foi distinto o comportamento das sementes quando em diferentes temperaturas. Assim, quando em vidro hermético (Figura $2 \mathrm{~A}$ ), a melhor temperatura para a germinação das sementes foi $30^{\circ} \mathrm{C}$ aos 2 meses, sendo $10^{\circ} \mathrm{C}$ a pior condição; dos 4 aos 12 meses, não houve diferença entre os efeitos das temperaturas e, a partir dos 10 meses, ocorreu rápida redução na porcentagem de germinação das sementes a $30^{\circ} \mathrm{C}$. A partir de 12 meses, $10^{\circ} \mathrm{C}$ e $20^{\circ} \mathrm{C}$, com efeito semelhante, foram as melhores condiçð̃es para armazenamento das sementes. Quando em saco de papel (Figura 2B), o efeito de $20^{\circ} \mathrm{C}$ foi semelhante ao de $30^{\circ} \mathrm{C}$, até 4 meses, sendo $10^{\circ} \mathrm{C}$ a pior temperatura de conservação. Por períodos mais longos, $20^{\circ} \mathrm{C}$ foi a melhor temperatura de conservação, diferindo das demais aos $6,8,12$ e 18 meses. A temperatura de $20^{\circ} \mathrm{C}$ não diferiu de $10^{\circ} \mathrm{C}$ aos 10 e 24 meses.

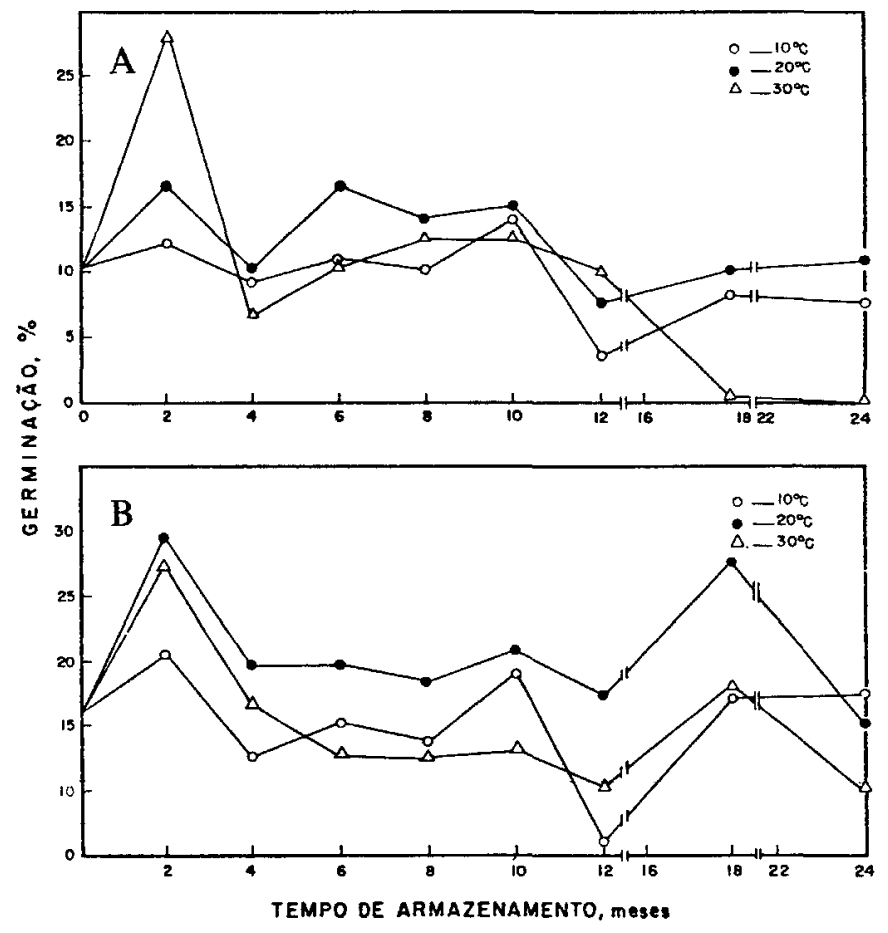

FIGURA 2 - Condiçбes de armazenamento de sementes secas, e seus efeitos na germinação em temperatura alternada de $20-30^{\circ} \mathrm{C}$ após 28 dias: A: Sementes armazenadas em vidro hermético, a diferentes condiçסes de temperatura; $B$ : Sementes armazenadas em saco de papel, a diferentes condiçбes de temperatura. 
Em sementes armazenadas frescas, a viabilidade foi afetada significativamente pelo tipo de embalagem. Os menores valores de viabilidade foram encontrados para sementes armazenadas em vidro hermético (Figura 3). A temperatura de conservação mostrou interação com o tipo de embalagem utilizado. Em vidro hermético a $10^{\circ} \mathrm{C}$, a viabilidade foi mantida por mais tempo, enquanto $30^{\circ} \mathrm{C}$ deteriorou rapidamente a semente. Foram obtidos valores intermediários para sementes armazenadas a $20^{\circ} \mathrm{C}$ (Figura $3 \mathrm{~A}$ ). Em saco de papel, a queda de viabilidade foi semelhante para as diferentes temperaturas, salientando-se apenas $20^{\circ} \mathrm{C}$ como a pior temperatura de conservação para períodos mais longos do que 10 meses (Figura 3B).

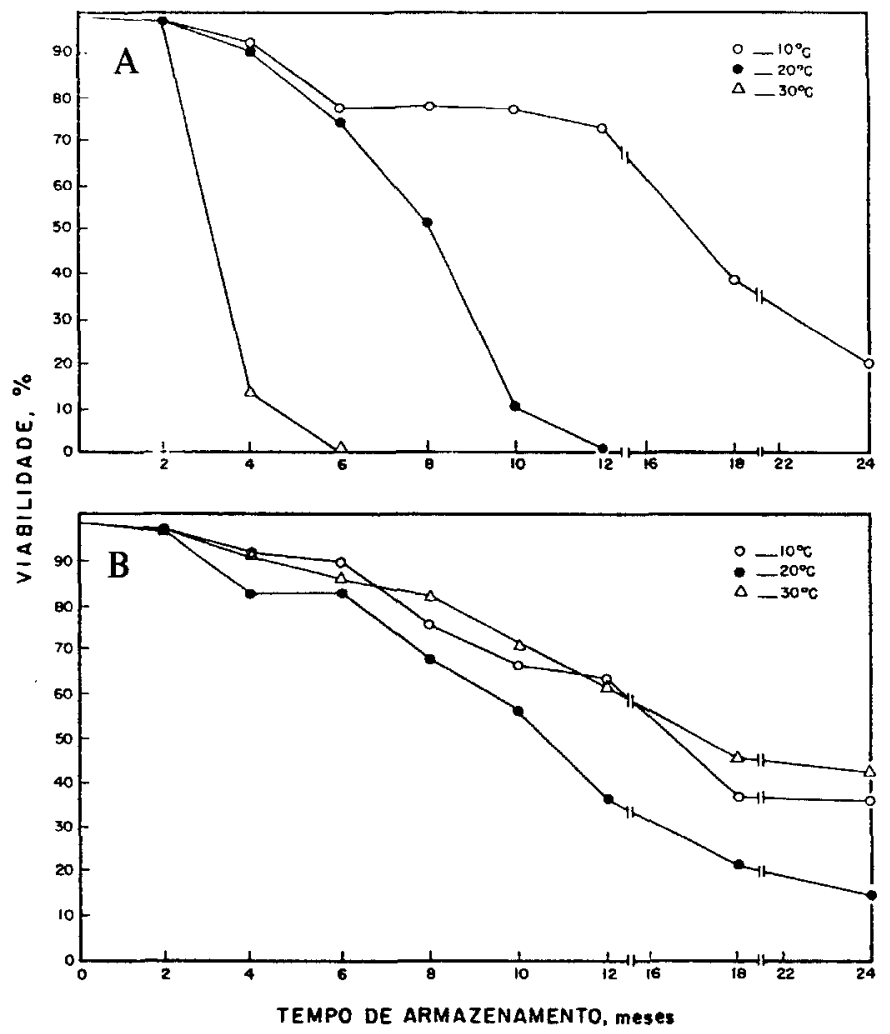

FIGURA 3 - Condiçбes de armazenamento de sementes frescas, e seus efeitos na viabilidade em temperatura alternada de $20-30^{\circ} \mathrm{C}$ após 28 dias: A: Sementes armazenadas em vidro hermético, a diferentes condiçoes de temperatura; $B$ : Sementes armazenadas em saco de papel a diferentes condiçסes de temperatura. 
Quando se estudou a viabilidade da semente armazenada seca, o efeito da embalagem só foi notado no período final de armazenamento (Figura 4), e a temperatura também só teve influência a partir de 12 meses de armazenamento. Em vidro hermético, $30^{\circ} \mathrm{C}$ ocasionou a maior deterioração das sementes. As temperaturas de 10 e $20^{\circ} \mathrm{C}$ tiveram efeitos semelhantes entre si (Figura 4A). Em saco de papel, a partir de 10 meses, $20^{\circ} \mathrm{C}$ foi a pior temperatura de conservação, enquanto as demais não diferiram entre si ( $\mathrm{Fi}$ !gura 4B).

Resumindo, o teste de germinação mostrou melhores resultados com o armazenamento das sementes a $20^{\circ} \mathrm{C}$. Apenas longos períodos de estocagem de sementes frescas em vidro hermético acusaram melhor comporta-

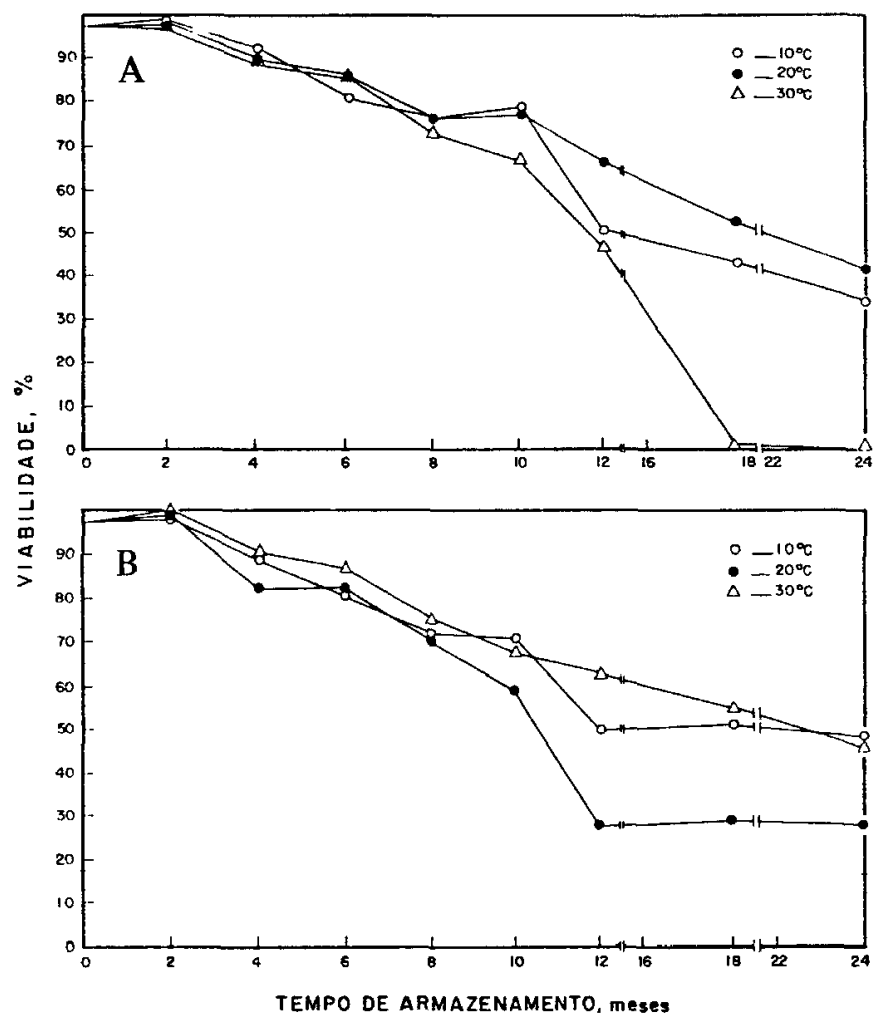

FIGURA 4 - Condiçoes de armazenamento de sementes secas, e seus efeitos na viabilidade em temperatura alternada de $20-30^{\circ} \mathrm{C}$ após 28 dias: A: Sementes armazenadas em vidro hermético, a diferentes condiçбes de temperatura; B: Sementes armazenadas em saco de papel, a diferentes condiçбes de temperatura. 
mento a $10^{\circ} \mathrm{C}$. Quanto à viabilidade das sementes, tamberm $20^{\circ} \mathrm{C}$ foi a melhor temperatura de conservação quando em vidro hermético, não diferindo de $10^{\circ} \mathrm{C}$ para as sementes secas. Em saco de papel, ao contrário, $20^{\circ} \mathrm{C}$ se mostrou a pior temperatura de conservação.

Analisando os resultados deste trabalho foi possível deduzir que a dormência da semente de uva não foi alterada pelo armazenamento nos diferentes tratamentos. Houve uma redução nos seus valores, refletindo, porém, apenas a perda natural de viabilidade das sementes.

\section{CONCLUSÕES}

a) A melhor temperatura de armazenamento para manter a capacidade de germinação da semente de uva foi $20^{\circ} \mathrm{C}$ tanto para sementes frescas como para secas.

b) Quando embaladas em vidro hermético, as sementes frescas de uva tiveram a viabilidade mais prolongada com $10^{\circ} \mathrm{C}$ de temperatura de conservação, e as secas mantiveram por mais tempo a viabilidade quando armazenadas a $20^{\circ} \mathrm{C}$.

c) Quando em saco de papel, ao contrário, $20^{\circ} \mathrm{C}$ mostrou-se a pior temperatura de conservação.

mento.

d) A dormência da semente de uva não foi alterada pelo armazena-

\section{SUMMARY}

\section{EFFECT OF STORAGE CONDITIONS ON THE VIABILITY AND DORMANCY OF GRAPE SEEDS}

Longevity of seeds is affected by the storage conditions, being temperature and seed moisture content the major factors to keep seeds viable. Experiments described here are concerned to the study of dormancy ant viability of seeds of grape cv. Patrícia, stored with two different moisture contents, either in moisture proof containers or paper bags, at temperatures of $10^{\circ} \mathrm{C}, 20^{\circ} \mathrm{C}$ and $30^{\circ} \mathrm{C}$, for 24 months. Samples were taken every two months during the first 12 months and at 6 months intervals in the second year, to determine seed viability and dormancy level. Storage, in the studied conditions, did not alter dormancy level of the seeds. When stored in hermetical conditions, fresh seeds (high moisture content) were viable for the longest periods, at $10^{\circ} \mathrm{C}$. Dry seeds in those conditions exhibited the longest period of viability at $20^{\circ} \mathrm{C}$. When seeds were stored in paper bags there were no marked differences among the treatments, except when storage was done for long periods. In this case, viability was first lost at $20^{\circ} \mathrm{C}$. In this way, dormancy level was not altered by storage, and seed longevity was significantly affected either by temperature or type of seed container used during storage.

Index terms: grape; seeds; storage; viability;germination; dormancy. 


\section{REFER ÊNCIAS BIBLIOGRÁFICAS}

BARTON, L. V. Seed preservation and longevity. New York, Interscience Publishers, 1961.216p.

BRASIL. Ministério da Agricultura. Departamento Nacional de Produção Vegetal. Regras para Análise de Sementes. Brasília, Divisão de Sementes e Mudas, 1976. 188p.

COSTACURTA, A.; CANCELLIER, L.; DONINI, B. \& MANNINO, P. Germinazione di semi radiostimolati in alcune cultivar di vite (Vitis vinifera). Rivista di Viticoltura e di Enologia, 31(10):411-419, 1978.

DELOUCHE, J. C. Physiology of seed storage. Mississippi, State College, Mississippi State University, 1968. 8p.

GOMES, F. P. Curso de estatística experimental, 3. ed. Piracicaba, Escola Superior de Agricultura "Luiz de Queiroz", 1963. 404p.

HARRINGTON, J. F. Seed storage and longevity In: KOZLOWSKI, T. T., ed. Seed Biology. New York, Academic Press, 1972. v.3, p. 145-245.

ROBERTS, E. H. Predicting the storage life of seeds. Seed Science and Technology, $1: 499-514,1973$.

SNEDECOR, G. W. Statistical methods. Ames, Iowa State University Press, 1962. 422p.

WINKLER, A. J. General Viticulture. Berkeley, University of California Press, 1965. 633p. 